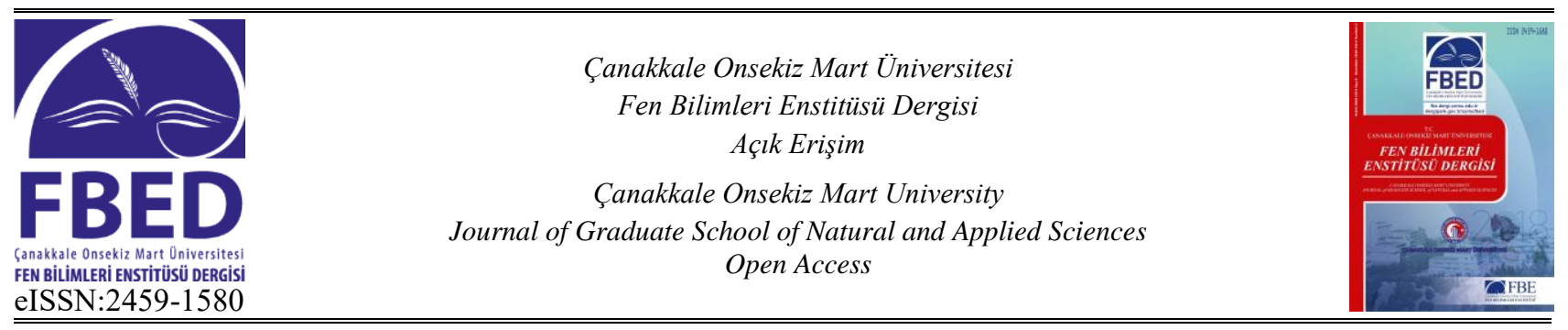

\title{
Benzimidazol-Oksadiazol Türevlerinin Sentezi ve Candida Türleri Üzerindeki Etkileri
}

\author{
Ulviye Acar Çevik ${ }^{1} *$, Derya Osmaniye ${ }^{1}$, Begüm Nurpelin Saglık ${ }^{1}$ \\ ${ }^{1}$ Farmasötik Kimya ABD, Eczacılık Fakültesi, Anadolu Üniversitesi, Eskişehir, Türkiye
}

$\begin{array}{lr}\text { Makale Tarihçesi } \\ \text { Gönderim: } & 06.08 .2019 \\ \text { Kabul: } & 10.01 .2020 \\ \text { Yayım: } & 22.05 .2020\end{array}$

Araştırma Makalesi
Öz - Günümüzde mantar enfeksiyonların tedavisinde kullanılan birçok ilaç bulunmasına rağmen, fungusların antifungal etkili ilaçlara kısa sürede rezistans kazanması, istenmeyen yan etkiler, toksik etkiler ve enfeksiyonlara karşı ideal özelliklere sahip kemoterapötik bileşiklerin henüz geliştirilememiş olması nedeniyle bu alandaki çalışmalar halen devam etmektedir. Heterosiklik kimyada benzersiz bir yere sahip olan benzimidazol son yillarda kimya ve farmakolojide çok yönlü özelliklerinden dolayı büyük ilgi görmüşlerdir. Benzimidazol bileşikleri birçok alanda önemli rol oynamakta olup aynı zamanda birçok ilacın yapısında bulunmaktadır. Bu grubu içeren ilaçlar antifungal, antimikrobiyal, antiinflamatuar, antikanser, antiviral, antidiyabetik vb. gibi birçok durumda terapötik bir etkiye sahiptir. Bu özellikleri nedeniyle, benzimidazol içeren ilaçların tüm klinik, farmakokinetik ve kimyasal çalışmaları, ilaç araştırmaları ve keşiflerinde son derece önem teşkil etmektedir. Bu çalışmada yeni benzimidazol-oksadiazol türevleri sentezlenmiş, spektroskopik analizler ile yapıları doğrulanmış, dört farklı Candida türü (Candida albicans, Candida glabrata, Candida krusei ve Candida parapsilopsis) üzerinde etkileri araştırılmıştır. Sentezlenen türevlerin yapıları ${ }^{1} \mathrm{H}-\mathrm{NMR}$, Kütle spektroskopik verileri ile aydınlatılmıştır. Gerçekleştirilen in vitro antifungal aktivite sonuçlarına göre, 5-klorobenzimidazol yapı iskeletine sahip olan $4 \mathrm{c}$ ve $4 \mathrm{~d}$ bileşiklerinin, $C$. glabrata'ya karşı $12.5 \mu \mathrm{g} / \mathrm{ml} \mathrm{MiK}_{50}$ değeri ile referans ilaç ketakonazol ile kıyaslandığında (MiK ${ }_{50}: 12.5 \mu \mathrm{g} / \mathrm{ml}$ ) seri içerisinde en umut verici bileşikler olduğu bulunmuştur.

\section{Synthesis of Benzimidazole-Oxadiazole Derivatives and Their Effects on Candida Species}

\author{
${ }^{1}$ Department of Pharmaceutical Chemistry, Faculty of Pharmacy, Anadolu University, Eskişehir, Turkey
}

\begin{abstract}
Article History
Received: $\quad 06.08 .2019$

Accepted: $\quad 10.01 .2020$

Published: $\quad 22.05 .2020$
\end{abstract}

Research Article

\begin{abstract}
Today, although there are a lot of drugs being used for fungus infections, much of the research still has been continued in this area on account of the unsatisfactory status of present treatment of fungus, drug side effects, toxic effects and the acquisition by the infecting organisms of the resistance to the present drugs. Benzimidazoles have occupied a unique position in heterocylic chemistry and its derivatives have attracted considerable interests in recent years for their versatile properties in chemistry and pharmacology. Drugs containing this group and its derivatives have a therapeutic effect in many cases such as antifungal, antimicrobial, anti-inflammatory, anticancer, antiviral, antidiabetic etc. Due to these properties, all clinic, pharmacokinetic and chemical studies of benzimidazole-containing drugs are extremely important in drug research and discovery. In this study, new benzimidazole-oxadiazole derivatives were synthesized, confirmed the structures by spectroscopic techniques, and their effects on four different Candida (Candida albicans, Candida glabrata, Candida krusei, Candida parapsilopsis) species were investigated. Structures of them were elucidated by ${ }^{1} \mathrm{H}-\mathrm{NMR}$, and Mass spectroscopic data. According to the results of in vitro antifungal activity, the compounds $4 \mathrm{c}$ and $4 \mathrm{~d}$, which features 5 -chlorobenzimidazole scaffolds, were found to be the most promising compounds in the series with a $\mathrm{MIC}_{50}$ value of $12.5 \mu \mathrm{g} / \mathrm{ml}$ against $C$. glabrata when compared to the reference drug ketoconazole $\left(\mathrm{MIC}_{50}: 12.5 / \mathrm{g} / \mathrm{ml}\right)$.
\end{abstract}

Keywords - Benzimidazole, 1,3,4-oxadiazole, Candida, Antifungal activity

\footnotetext{
1 http://orcid.org/0000-0003-1879-1034 uacar@anadolu.edu.tr

2 http://orcid.org/0000-0002-0151-6266 bnsaglik@ anadolu.edu.tr

3 http://orcid.org/0000-0002-0499-436X dosmaniye@ anadolu.edu.tr

*Sorumlu Yazar / Corresponding Author
} 


\section{Giriş}

Son yıllarda fungus enfeksiyonu vakaları ciddi bir biçimde artış göstermiştir. Bu artışın nedenleri arasında yoğun ve uzun süren kemoterapi tedavisi, yüksek dozlu kortikosteroid tedavisi, uzun süren antibiyotik tedavisi ve immün yetersizlik yer almaktadır (Ellis, 2002). Bu enfeksiyonların tedavisinde amfoterisin B toksisitesine rağmen uzun yıllar önemli bir yere sahip olmuştur. Sonrasında azol grubu ilaçların keşfi farklı tedavi olanakları sunmuştur. En son ekinokandinler antifungal tedaviye girmiştir. $\mathrm{Bu}$ antifungallerin birçoğunun amfoterisin B'ye göre daha az toksik olduğu ve bazı durumlarda daha etkili olduğu kanıtlanmıştır, ancak yoğun kullanımları nedeniyle bu antifungallere de dirençli suşlar gelişmeye başlamıştır (Ostrosky-Zeichner, 2003; Chandrasekar, 2001). Araştırmacıların çoğu mevcut ilaçlardan farklı yapıya sahip yeni moleküllerin geliştirilmesiyle direnç gelişiminin önlenebileceğini düşünmektedirler.

Antifungal ilaçlara karşı oluşan doğal (primer) ve kazanılmış (sekonder) direnç olmak üzere iki farklı direnç çeşidi bulunmaktadır. Doğal direnç, bir cins ya da türün daha önce o ilaç ile karşılaşmasının etkisi olmaksızın o ilaca dirençli oluşuyken, kazanılmış direnç mantarın antifungal ilaç ile tedavi sonucunda veya bir başka yolla karşılaşması sonucunda suşun dirençli hale geçmesidir (Revie, 2018; Wiederhold 2017).

Her antifungal ilacın etki mekanizması farklı olduğu için, gelişen direnç mekanizmaları da farklılık göstermektedir. Örneğin, Candida türlerinin azol sınıfı antifungallere direnç geliştirmede başlıca dört temel mekanizması bulunmaktadır. Bunlar ilaç konsantrasyonunun dışa atım pompaları (effluks sistemi) ya da ilaç penatrasyonunun azaltılması, hedef bölgenin modifikasyonu, hedef enzimin düzenlenmesi ve baypas yollarının geliştirilmesi şeklindedir. Ancak Candida türlerinin ekinokandinlere direnç ise FKS (1,3-betaglukan sentaz) genlerinde meydana gelen mutasyon ile gerçekleşmektedir (Pfaller, 2012; Zimbech, 2010).

Antimikrobiyal aktivite çalışmalarına bakıldığında üzerinde yoğun olarak çalışılan benzimidazol türevi benzazoller özellikle göze çarpmaktadır. Benzimidazol halkası pürin antimetaboliti ve vitamin B12 ile bazı aminoasitlerin yapısında doğal olarak bulunduğundan canlı organizma tarafından tanınması ve etkileşimi kolaydır. Astemizol, mebendazol, enviroksim, karbendazim ve benomil gibi bazı benzimidazol türevlerinin bakteri büyümesini önlediği de literatürlerde kayıtlıdır (Pawar, 2004; Saleh, 2010). Şekil 1'de benzimidazol yapısı içeren antimikrobiyal etkili bileşiklere örnek verilmiştir.

Benzimidazole grubu fungisitler iğ iplikçiklerinin yapısını oluşturan tubulin'in biyosentezini engelleyerek etki yaparlar. Bunun sonucunda metafaz döneminde kromozomların ayrılması durdurularak hücre bölünmesine ve buna bağlı olarak da hif ucu gelişmesine engel olurlar (Demirci, 1996).

Azol türevi antifungal ilaçlar mantar hücrelerinin sitoplazma membranındaki ana sterol bileşiği olan ergosterol sentezini, 14-metillanosterol'un demetil dehidrolansterole dönüşümü basamağında inhibe eder. Bu dönüşümü yapan 14- $\alpha$-demetilaz enzimi bir mikrozomal sitokrom P450 türüdür. Azol türevi ilaçlar bu sitokrom P450'yi selektif olarak inhibe eder. Mantarların sitokrom P450 si imidazol türevlerine memelilerin aynı enzimine kıyasla $1000 \mathrm{kez}$ daha duyarlıdır. Azollere maruz kalan mantar hücrelerinde 14-alfametilsterol birikir ve bunlar membran fosfolipidlerinin asıl zincirlerinin normal düzenini ve membrana bağlı belli enzimlerin fonksiyonlarını bozarlar, sonuçta mantar hücrelerinin büyümeleri inhibe edilir; ayrıca hücre membranının permeabilitesi bozulur (Altındağ, 2019; Işık 2019).

Azollerin ve benzimidazol halkasının etki mekanizmaları göz önüne alınarak yeni benzimidazol-1,3,4oksadiazol yapısı taşıyan dört adet bileşik sentezlenmiş ve dört farklı Candida türü üzerinde etkileri incelenmiştir. 
<smiles>CCCCNC(=O)n1c(NC(=O)OC)nc2ccccc21</smiles>

Benomil<smiles>COC(=O)Nc1nc2ccccc2[nH]1</smiles>

Karbendazim<smiles>c1ccc2[nH]c(-c3cscn3)nc2c1</smiles>

Thiabendazole

Şekil 1. Benzimidazol yapısı içeren bazı fungusit ilaç örnekleri

\section{Materyal ve Yöntem}

\subsection{Sentez Çalışmaları}

\section{Metil 4-(5(6)-sübstitüe-1H-benzimidazol-2-il) benzoat (1a, 1b) türevlerinin sentezi}

Mikrodalga sentez reaktörü viali $(30 \mathrm{~mL})$ içerisine metil 4-formilbenzoat (4.8 g, $0.03 \mathrm{~mol})$, sodyum disülfit $(5.7 \mathrm{~g}, 0.03 \mathrm{~mol})$ ve dimetilformamid $(10 \mathrm{~mL})$ konulmuştur. Reaksiyon karışımı mikrodalga sentez reaktöründe $240{ }^{\circ} \mathrm{C}$ 'de 10 bar basınç altında 5 dakika tutulmuştur. Bu süre sonunda karışım reaktörden çıkartılarak üzerine 5-kloro veya 5-floro-1,2-fenilendiamin (0.03 mol) ilave edilmiş ve aynı reaksiyon şartlar altında 5 dakika daha mikrodalga 1şımasına tabi tutulmuştur. Reaksiyon süresi bitiminde ürün buzlu suya dökülerek çöktürülmüş, süzüldükten sonra bol su ile yıkanmış ve etonolden kristallendirilmiş̧ir (Acar Çevik, 2017). Verim: \%77-82.

\section{4-(5(6)-sübstitüe-1H-benzimidazol-2-il)benzoik asid hidrazid türevlerinin (2a, 2b) sentezi}

Mikrodalga sentez reaktörü viali $(30 \mathrm{~mL})$ içerisine metil 4-(5-sübstitüe-1 $H$-benzimidazol-2-il) benzoat $(0.02$ mol), etanol $(15 \mathrm{~mL})$ ve hidrazin hidrat $(5 \mathrm{~mL})$ ilave edilmiştir. Reaksiyon karışımı mikrodalga sentez reaktöründe $240{ }^{\circ} \mathrm{C}$ 'de 10 bar basınç altında 10 dakika tutulmuştur. Reaksiyon bitiminde ürün buzlu suya dökülerek çöktürülmüş, süzüldükten sonra bol su ile yıkanmış ve etonolden kristallendirilmiştir (Acar Çevik, 2017) Verim \%82-89.

\section{5-[4-(5(6)-sübstitüe-1H-benzimidazol-2-il) fenil]-1,3,4-oksadiazol-2-tiol türevlerinin (3a,3b) sentezi}

4-(5(6)-sübstitüe-1 $H$-benzimidazol-2-il) benzoik asid hidrazid türevlerinin (2a, 2b) (0.031 mol) etanol (150 $\mathrm{mL})$ içerisindeki çözeltisine $\mathrm{NaOH}(1.48 \mathrm{~g}, 0.037 \mathrm{~mol})$ eklenmiştir. Karbon disülfür $(2.24 \mathrm{~mL}, 0.037 \mathrm{~mol})$ eklendikten sonra, karışım 8 saat geri çeviren soğutucu altında karıştırılmıştır. Bu süreden sonra, çözelti soğutulmuş ve hidroklorik asit çözeltisi ile pH 4-5'e asitleştirilerek çöken ürün süzülmüştür (Karaburun, 2019) Verim: \%77-72.

2-[(5-(4-(5(6)-sübstitüe-lH-benzimidazol-2-il)fenil)-1,3,4-oksadiazol-2-il)tiyo]-1-(3,4-disübstitüefenil)etan1-on türevlerinin sentezi $(4 a-4 d)$

5-[4-(5(6)-sübstitüe-1H-benzimidazol-2-il) fenil]-1,3,4-oksadiazol-2-tiol türevleri (3a, 3b) (2mmol) aseton içerisinde çözündürülerek üzerine 3,4-disübstitüefenaçil bromür türevleri $(2,4 \mathrm{mmol})$ eklenmiştir. Reaksiyonun bitimi ince tabaka kromatografisi ile kontrol edilmiştir. Reaksiyonun bitiminde aseton uçurulmuş, kalıntı su ile yıkanarak alınmıştır (Karaburun, 2019) 
zimidazole $\mathrm{CH}), 7.42(1 \mathrm{H}, \mathrm{s}$, Benzimidazole $\mathrm{CH}), 7.62(1 \mathrm{H}, \mathrm{s}$, Benzimidazole $\mathrm{CH}), 8.12(2 \mathrm{H}, \mathrm{d}, \mathrm{J}=8.49 \mathrm{~Hz}$, 1,4-Disübstitüebenzen), 8.25-8.35 (4H, m, 1,4-Disübstitüebenzen), $8.40 \quad(2 \mathrm{H}, \mathrm{d}, J=8.88 \mathrm{~Hz}, \quad 1,4-$ Disübstitüebenzen), $13.26(1 \mathrm{H}, \mathrm{s},-\mathrm{NH})$. ESI-MS [M+H] $]^{+}: 447$.

2-[(5-(4-(5(6)-floro-lH-benzimidazol-2-il)fenil)-1,3,4-oksadiazol-2-il)tiyo]-1-(3,4-diflorofenil)etan-1-on (4b): Yields: $72 \%$. Mp $242.7{ }^{\circ} \mathrm{C}$. ${ }^{1} \mathrm{H}-\mathrm{NMR}\left(300 \mathrm{MHz}, \mathrm{DMSO}-d_{6}\right): \delta=5.07\left(2 \mathrm{H}, \mathrm{s},-\mathrm{CH}_{2}-\right), 7.10(1 \mathrm{H}, \mathrm{s}$, Benzimidazole $\mathrm{CH}$ ), 7.31-7.32 (1H, m, Benzimidazole $\mathrm{CH})$, 7.49-7.57 (3H, m, Benzimidazol $\mathrm{CH}$ ve fenil $\mathrm{CH})$, 8.04-8.05 (1H, m, fenil $\mathrm{CH}), 8.11(2 \mathrm{H}, \mathrm{d}, J=8.58 \mathrm{~Hz}, 1,4-$ Disübstitüebenzen), 8.35 (2H, d, $J=8.49 \mathrm{~Hz}, 1,4-$ Disubstituebenzen), 13.27 (1H, s, -NH). ESI-MS [M+H] $]^{+}: 467$.

2-[(5-(4-(5(6)-kloro-lH-benzimidazol-2-il)fenil)-1,3,4-oksadiazol-2-il)tiyo]-1-(4-hidroksi-fenil)etan-1-on (4c): Yields:68 \%. Mp $281.7^{\circ} \mathrm{C} .{ }^{1} \mathrm{H}-\mathrm{NMR}\left(300 \mathrm{MHz}, \mathrm{DMSO}-d_{6}\right): \delta=5.19\left(2 \mathrm{H}, \mathrm{s},-\mathrm{CH}_{2}-\right), 7.24-7.27(1 \mathrm{H}, \mathrm{m}$, Benzimidazole CH), $7.58(2 \mathrm{H}, \mathrm{s}$, Benzimidazole $\mathrm{CH}), 7.81(2 \mathrm{H}, \mathrm{d}, J=8.58 \mathrm{~Hz}, 1,4$-Disübstitüebenzen), 8.01 ( $2 \mathrm{H}, \mathrm{d}, J=8.58 \mathrm{~Hz}, 1,4$-Disübstitüebenzen), $8.11(2 \mathrm{H}, \mathrm{d}, J=8.55 \mathrm{~Hz}, 1,4$-Disübstitüebenzen), 8.33 (2H, d, $J=8.55 \mathrm{~Hz}, 1,4-$ Disübstitüebenzen), $13.32(1 \mathrm{H}, \mathrm{s},-\mathrm{NH})$. ESI-MS [M+H] ${ }^{+}: 463$.

2-[(5-(4-(5(6)-kloro-lH-benzimidazol-2-il)fenil)-1,3,4-oksadiazol-2-il)tiyo]-1-(3,4-diflorofenil)etan-1-on (4d): Yields:68 \%. Mp $252.7{ }^{\circ} \mathrm{C} .{ }^{1} \mathrm{H}-\mathrm{NMR}\left(300 \mathrm{MHz}, \mathrm{DMSO}-d_{6}\right): \delta=5.05\left(2 \mathrm{H}, \mathrm{s},-\mathrm{CH}_{2}\right), 7.23-7.33(2 \mathrm{H}, \mathrm{m}$, Ar-CH), 7.46-7.54 (1H, m, Ar-CH), $7.64(2 \mathrm{H}, \mathrm{s}, \mathrm{Ar}-\mathrm{CH}), 8.04-8.09$ (1H, m, fenil CH), 8.11 (2H, d, $J=8.49$ $\mathrm{Hz}, 1,4$-Disübstitüebenzen), 8.35 (2H, d, $J=8.49 \mathrm{~Hz}, 1,4-$ Disubstituebenzen), 13.35 (1H, s, -NH). ESI-MS $[\mathrm{M}+\mathrm{H}]^{+}: 483$

\section{2. İnce Tabaka Kromatografi Çalışmaları ve $R_{f}$ Değerlerinin Saptanması}

Anlatılan bütün sentez çalışmalarında reaksiyonların kontrolü İTK uygulamaları ile gerçekleştirilmiştir. Belli zaman aralıkları ile deney balonlarından alınan numuneler ve sentezler de kullanılan başlangıç maddelerinin etanoldeki çözeltileri adsorban olarak seçilen silikajel $60 \mathrm{~F}_{254}$ kaplı, önceden uygun çözücü karışımları ile doyurulmuş alüminyum plaklara kılcal boru yardımıyla tatbik edilmiş ve hareketli fazlar içerisinde sürüklenmesi sağlanmıştır. Lekelerin saptanmasında, ultraviyole 1 şığı $(254 \mathrm{~nm}$ ve $366 \mathrm{~nm})$ kullanılmıştır. İTK sonucuna göre reaksiyonlara son verilmiş ya da devam edilmiştir. Çalışma kapsamındaki her bir sentezin kontrolü için uygun İTK hareketli fazları, farklı çözücü karışımları denenerek bulunmuştur. Yöntem A, B ve C'de anlatılan sentezlerin kontrolü için uygun hareketli fazın petrol eteri : etil asetat ( $3: 1)$, yöntem D'deki sentezin kontrolü için uygun hareketli fazın petrol eteri : etil asetat (1:1), olduğuna karar verilmiştir.

\subsection{Erime Noktalarının Tespiti}

Sentezlenen bileşiklerin erime noktalarının (E.n) saptanması, toz edilen maddenin, bir ucu açık kapiler borulara $1 / 2 \mathrm{~cm}$ kadar doldurularak Elektrotermal erime noktası tayini cihazında yapılmış ve bulunan değerler düzeltilmemiştir.

\section{4. ${ }^{1}$ H NMR Spektrumlarının Alınması}

Çalışma kapsamındaki sonuç bileşiklerin ${ }^{1} \mathrm{H}$ NMR spektrumları, $5 \mathrm{mg}$ sentez ürününün $0.5 \mathrm{ml}$ dötöryo dimetilsülfoksid içindeki çözeltisinin, tetra metil silan’a karşı 300 MHz’lik NMR spektrometresine uygulanması sonucu alınmıştır.

\subsection{Kütle Analizi}

$1 \mathrm{mg}$ madde tartılarak $1 \mathrm{ml}$ asetonitril-su karışımında çözülmüş, LC-MS-MS (Shimadzu Kyoto, Japonya) cihazı kullanılarak analiz edilmiştir. 


\subsection{Antifungal Aktivite}

Antifungal aktivite testi EUCAST kesin yöntemi EDef 7.1'e göre gerçekleştirilmiştir. Sentezlenen bileşikler, C. glabrata (ATCC 90030), C. krusei (ATCC 6258), C. parapsilosis'e (ATCC 22019) ve $C$. albicans'a (ATCC 24433) karşı in vitro büyüme önleyici aktiviteleri için test edilmiştir.

Maya suşları canlandırılmak üzere $-85^{\circ} \mathrm{C}$ 'den çıkarılarak içinde Sabouraud Dextrose Agar (SDA) bulunan petrilere ekilmiş ve $37^{\circ} \mathrm{C}$ 'de 24 saat süreyle inkübasyona bırakılmıştır. İnkübasyondan sonra gelişen kültürlerin, McFarland $0.5-2.5 \times 10^{5} \mathrm{cfu} / \mathrm{mL}$ tüpüne göre bulanıklık ayarı yapılmıştır.

Test edilecek bileşikler, $1.6 \mathrm{mg}$ olmak üzere tartılarak steril flakonlara aktarılmış ve üzerlerine $2 \mathrm{~mL}$ saf DMSO eklenmiştir. Bileşiklerin dimetilsülfoksit içinde tam olarak çözünmeleri ve homojen bir karışım hale gelmeleri sağlanmıştır. Bileşiklerin $800,400,200,100,50,25,12.5,6.25,3.125,1.56$ ve $0.78 \mu \mathrm{g} / \mathrm{ml}$ olarak dilüsyonları hazırlanmıştır.

Deney için 96 "U” tipi kuyucuklara sahip mikrotitrasyon petrileri (Brand) kullanılmıştır. Hazırlanmış bileşik karışımları mikropipetörler yardımıyla $100 \mu \mathrm{L}$ olacak şekilde sırasıyla kuyucuklara aktarılmıştır. Tüm konsantrasyonlar kuyucuklara aktarıldıktan sonra, maya kültürlerinden 100 'er $\mu 1$ pipetlenmiştir. Son sütun mikroorganizma kontrolüne, son satır da test maddesinin kontrolüne ayrılmıştır. Bu işlemlerden sonra mikrotitrasyon petrilerinin kapakları kapatılarak $37^{\circ} \mathrm{C}$ 'de 24 saat inkübasyona bırakılmış ve bu süre sonunda kuyucuklarda üremenin varlığının ya da yokluğunun daha iyi gözlenebilmesi için her kuyuya resazurin (20 ug / $\mathrm{mL}$ ) ilave edilmiştir. Daha sonra renklenme için $37^{\circ} \mathrm{C}$ 'de 3 saat daha inkübasyona bırakılmıştır. İnkübasyon süresi sonunda üremenin gözlenmediği en düşük konsantrasyon yani minimum inhibe edici konsantrasyon $\left(\mathrm{MIK}_{50}\right) \mu \mathrm{g} / \mathrm{mL}$ olarak belirlenmiştir. Deneyler çift paralel olarak tekrarlanmıştır. Standart antifungal madde olarak ketakonazol kullanılmıştır.

\section{Bulgular ve Tartışma}

Sentez çalışmaları 4 basamakta gerçekleştirilmiş ve Şekil 2'de gösterilmiştir. Sentezi gerçekleştirilen bileşiklerin fonksiyonel grupları Tablo 1'de verilmiştir. Sentez çalışmalarının birinci basamağında metil 4formil benzoat ile sodyum disülfit, dimetilformamid içerisinde mikrodalga 1şıması altında reaksiyona tabi tutulmuş, elde edilen benzaldehit sodyum bisülfit katım ürünü ile 3,4-diamino benzoik asit'in mikro dalga 1şımas1 altında meydana gelen kondenzasyon reaksiyonu sonucunda Metil 4-(5(6)-sübstitüe-1Hbenzimidazol-2-il) benzoat (1a, 1b) türevleri elde edilmiştir. Bir sonraki basamakta 1a-1b bileşikleri mikrodalga 1şıması altında hidrazin hidrat ile muamele edilerek 4-(5(6)-sübstitüe-1H-benzimidazol-2il)benzoik asid hidrazid (2a, 2b) bileşikleri elde edilmiştir. Sentezlenen hidrazit türevlerinin (2a, 2b) etanol içerisinde, bazik ortamda karbon disülfür ile oksadiazol halkası kapanmasına yönelik reaksiyonu sonucu 5[4-(5(6)-sübstitüe-1H-benzimidazol-2-il) fenil]-1,3,4-oksadiazol-2-tiol (3a,3b) bileşikleri kazanılmıştır. Son reaksiyon basamağı 3a, 3b türevleri ile 3,4-disübstitüefenaçil bromür türevleri arasında gerçekleştirilmiş ve 2-[(5-(4-(5(6)-sübstitüe-1 $H$-benzimidazol-2-il)fenil)-1,3,4-oksadiazol-2-il)tiyo]-1-(3,4-disübstitüefenil)etan1-on (4a-4d) hedef bileşikleri elde edilmiştir. 
<smiles>[R]c1ccc(N)c(N)c1</smiles><smiles>[R]c1ccc2nc(-c3ccc(C(=O)NN)cc3)[nH]c2c1</smiles><smiles>[R]c1ccc2nc(-c3ccc(-c4nnc(S)o4)cc3)[nH]c2c1</smiles><smiles>[R]c1ccc2[nH]c(-c3ccc(-c4nnc(SCC(=O)c5ccc([R3])c([R])c5)o4)cc3)nc2c1</smiles>

Şekil 2. 4a-4d Kodlu bileşiklerin sentez şeması

Tablo 1. 4a-4d bileşiklerine ait fonksiyonel gruplar

\begin{tabular}{llll}
\hline Bileşik & $\mathbf{R}_{\mathbf{1}}$ & $\mathbf{R}_{\mathbf{2}}$ & $\mathbf{R}_{\mathbf{3}}$ \\
$\mathbf{4 a}$ & $-\mathrm{F}$ & $-\mathrm{H}$ & $\mathrm{OH}$ \\
$\mathbf{4 b}$ & $-\mathrm{F}$ & $-\mathrm{F}$ & $-\mathrm{F}$ \\
$\mathbf{4 c}$ & $-\mathrm{Cl}$ & $-\mathrm{H}$ & $\mathrm{OH}$ \\
$\mathbf{4 d}$ & $-\mathrm{Cl}$ & $-\mathrm{F}$ & $-\mathrm{F}$ \\
\hline
\end{tabular}

Sentezi gerçekleştirilen Benzimidazol-oksadiazol türevlerinin antifungal etki potansiyelleri mikrodilüsyon tekniği kullanılarak çeşitli Candida türleri üzerinde test edilmiştir. Mikrobiyolojik çalışmalar sonucunda her bileşik için mikroorganizmalara karşı gözlenen Minimum İnhibitör Konsantrasyon $\left(\mathrm{MIK}_{50}\right)$ değeri kaydedilmiştir. Aktivite çalışmalarında fungus türleri olarak Candida krusei, Candida albicans, Candida parapsilosis ve Candida glabrata kullanılmıştır. Sentez edilen bileşiklerin antifungal etkinliklerini karşılaştırmak amacıyla standart ajan olarak triazol halkası taşıyan ketakonazol kullanılmıştır. Mikrobiyolojik çalışmalar sonucunda elde edilen MíK $_{50}$ değerleri Tablo 2'de sunulmuştur.

Antifungal aktivite sonuçları incelendiğinde sentezlenen bileşiklerin 12.5-50 $\mu \mathrm{g} / \mathrm{mL}$ arasında MíK ${ }_{50}$ değerlerine sahip oldukları görülmektedir. Seri içerisinde 4c ve 4d kodlu bileşiklerin $12.5 \mu \mathrm{g} / \mathrm{mL}$ MİK $_{50}$ değeri ile en aktif bileşikler oldukları bulunmuştur. Ayrıca bu bileşiklerin C. glabrata'ya karşı referans ilaç ketakonazol ile aynı düzeyde etki potansiyeline sahip oldukları görülmektedir. 4c ve $4 \mathrm{~d}$ kodlu bileşiklerin yapıları incelendiğinde benzimidazol halkasının 5. konumunda klor sübstitüentleri taşıdıkları görülmektedir. Aktivite sonuçları ve sentezlenen bileşiklerin yapıları 
değerlendirildiğinde benzimidazol halkası üzerinde klor sübstitüentinin bulunmasının aktiviteyi arttırdığı bulunmuştur.

Daha önce yaptığımız çalışmanın sonuçlarına baktığımızda (Karaburun, 2019) fenil halkası üzerinde 3. ve 4. konumlarda hidroksi grubunun olmasının aktiviteyi önemli derecede arttırdı̆̆ görülmektedir. $\mathrm{Bu}$ çalışmada $4 \mathrm{a}$ ve $4 \mathrm{c}$ kodlu bileşiklerde sadece 4 . konumda hidroksi grubu bulunmaktadır. Aktiviteyi karşılaştırdığımızda sadece 4. konumda hidroksil grubunun bulunması $C$. albicans'a karşı aktiviteyi düşürdüğü görülmektedir. $\mathrm{Bu}$ çalışma kapsamında sentezlenen bileşiklerin daha önceki çalışmamıza göre (Karaburun, 2019) aktivitelerinin daha yüksek olduğu dikkat çekmektedir. Fenil halkası üzerinde iki tane flor sübstitüentinin bulunması aktiviteyi önemli derecede artırmıştır.

Tablo 2. Sentezlenen bileşiklere ait MíK$_{50}(\mu \mathrm{g} / \mathrm{mL})$ değerleri

\begin{tabular}{rcccc}
\hline Bileşik & C. krusei & C. glabrata & C. albicans & C. parapsilosis \\
& & & & \\
\hline 4a & 25 & 25 & 50 & 25 \\
4b & 25 & 25 & 50 & 25 \\
4c & 50 & 12.5 & 50 & 50 \\
4d & 50 & 12.5 & 25 & 25 \\
Ketakonazol & 6.25 & 12.5 & 12.5 & 6.25 \\
\hline
\end{tabular}

\section{Sonuçlar}

Bu çalışma kapsamında Benzimidazol-oksadiazol halka sisteminin sahip olduğu potansiyel antifungal etki dikkate alınarak 4 adet yeni bileşik sentezlenmiştir. Elde edilen bileşiklerin yapıları ${ }^{1} \mathrm{H}-\mathrm{NMR}$ ve kütle spektroskopik yöntemleri ile aydınlatılmıştır. Sentez bileşikleri antifungal etki testlerine tabi tutulmuş ve $\mathrm{MIK}_{50}$ değerleri kaydedilmiştir. Elde edilen mikrobiyolojik bulgular $4 \mathrm{c}$ ve $4 \mathrm{~d}$ kodlu bileşiklerin antifungal etki potansiyelinin $C$. glabrata türü üzerinde referans ilaç ile aynı düzeyde olduğunu göstermiştir. Zorlu bir süreç olan yeni ilaç etkin maddesi geliştirme zincirinin ilk halkasını oluşturan Farmasötik Kimya alanında yapılan bu çalışmadan elde edilen antifungal aktivite sonuçları umut verici niteliktedir. Bu nedenle, bu çalışma sonuçlarına göre, ileride gerçekleştirilecek çalışmalarda benzimidazol-oksadiazol yapısı içeren yeni bileşiklerin antifungal aktivitelerinin araştırılması önerilmektedir.

\section{Yazar Katkıları}

Ulviye ACAR ÇEVIK: Çalışmayı planlamış ve makalenin yazımını gerçekleştirmiştir.

Derya OSMANIYE: Bileşiklerin analizini gerçekleştirmiştir.

Begüm Nurpelin SAĞLIK: Bileşiklerin aktivitelerini gerçekleştirmiştir.

\section{6. Çıkar Çatışması}

Yazarlar çıkar çatışması bildirmemişlerdir. 


\section{Kaynaklar}

Acar Cevik, U., Nurpelin Saglik, B., Ozkay, Y., Canturk, Z., Bueno, J., Demirci, F. ve Savas Koparal, A. (2017). Synthesis of new fluoro-benzimidazole derivatives as an approach towards the discovery of novel Intestinal antiseptic drug candidates. Current Pharmaceutical Design, 23(15), 2276-2286. Erişim adresi:

https://doi.org/10.2174/1381612822666161201150131.

Altındağ, F. D., Sağlık, B. N., Acar Çevik, U., Işıkdağ, İ., Özkay, Y. ve Karaca Gençer, H. (2019). Novel imidazole derivatives as antifungal agents: Synthesis, biological evaluation, ADME prediction and molecular docking studies. Phosphorus, Sulfur, and Silicon and the Related Elements, 194 (9), 887-894. Erişim adresi: https://doi.org/10.1080/10426507.2019.1565761.

Chandrasekar, P. H., Cutright, J. L. ve Manavathu, E. K. (2001). Aspergillus: rising frequency of clinical isolation and continued susceptibility to antifungal agents, 1994-1999. Diagnostic Microbiology and Infectious Disease, 41(4), 211-214. Erişim adresi: https://doi.org/10.1016/S0732-8893(01)00295-4.

Demirci, E. (1996). Fungisitlere karşı dayanıklılı̆̆ın gelişimi ve yönetimi. Atatürk Üniversitesi Ziraat Fakültesi Dergisi,27(4), 576-588. Erişim adresi: https://dergipark.org.tr/en/download/article-file/34525.

Ellis, M. (2002). Invasive fungal infections: evolving challenges for diagnosis and therapeutics. Molecular Immunology, 38(12-13), 947-957. Erişim adresi: https://doi.org/10.1016/S01615890(02)00022-6.

EUCAST. (2008). Definitive Document EDef 7.1: Method for the Determination of Broth Dilution MICs of Antifungal Agents for Fermentative Yeasts. Clinical Microbiology and Infection, 14, 398-405. Erişim adresi: https://doi.org/10.1111/j.1469-0691.2007.01935.x.

Işık, A., Acar Çevik, U., Sağlık, B. N. ve Özkay, Y. (2019). Synthesis, Characterization, and Molecular Docking Study of Some Novel Imidazole Derivatives as Potential Antifungal Agents. Journal of Heterocyclic Chemistry, 56(1), 142-152. Erişim adresi: https://doi.org/10.1002/jhet.3388.

Karaburun, A., Kaya Çavuşoğlu, B., Acar Çevik, U., Osmaniye, D., Sağlık, B., Levent, S., Ozkay, Y., Atlı, Ö., Koparal, A.S. ve Kaplancıkl1, Z. (2019). Synthesis and Antifungal Potential of Some Novel Benzimidazole-1,3,4-Oxadiazole Compounds. Molecules, 24(1), 191. Erişim adresi: https://doi.org/10.3390/molecules24010191.

Ostrosky-Zeichner, L., Marr, K. A., Rex, J. H. ve Cohen, S. H. (2003). Amphotericin B: time for a new" gold standard". Clinical Infectious Diseases, 37(3), 415-425. Erişim adresi: https://www.jstor.org/stable/4462462.

Pawar, N. S., Dalal, D. S., Shimpi, S. R. ve Mahulikar, P. P. (2004). Studies of antimicrobial activity of $\mathrm{N}$-alkyl and $\mathrm{N}$-acyl 2-(4-thiazolyl)-1H-benzimidazoles. European Journal of Pharmaceutical Sciences, 21(2-3), 115-118. Erişim adresi: https://doi.org/10.1016/i.ejps.2003.09.001.

Pfaller, M. A. (2012). Antifungal drug resistance: mechanisms, epidemiology, and consequences for treatment. The American Journal of Medicine, 125(1), 3-13. Erişim adresi: https://doi.org/10.1016/j.amjmed.2011.11.001.

Revie, N. M., Iyer, K. R., Robbins, N. ve Cowen, L. E. (2018). Antifungal drug resistance: evolution, mechanisms and impact. Current Opinion in Microbiology, 45, 70-76. Erişim adresi: https://doi.org/10.1016/j.mib.2018.02.005.

Saleh, M., Abbott, S., Perron, V., Lauzon, C., Penney, C. ve Zacharie, B. (2010). Synthesis and antimicrobial activity of 2-fluorophenyl-4, 6-disubstituted [1,3,5] triazines. Bioorganic Medicinal Chemistry Letters, 20(3), 945-949. Erişim adresi: https://doi.org/10.1016/j.bmcl.2009.12.063. 
Wiederhold, N.P. (2017). Antifungal resistance: current trends and future strategies to combat. Infection and drug resistance, 10, 249-259. Erişim adresi: https://doi.org/10.2147/IDR.S124918.

Zimbeck, A. J., Iqbal, N., Ahlquist, A. M., Farley, M. M., Harrison, L. H., Chiller, T. ve Lockhart, S. R. (2010). FKS mutations and elevated echinocandin MIC values among Candida glabrata isolates from US population-based surveillance. Antimicrobial Agents and Chemotherapy, 54(12), 5042-5047. Erişim adresi: https://doi.org/10.1128/AAC.00836-10. 